\title{
Adequações tecnológicas no processamento da carne de caranguejo
}

\author{
Technological improvements in mangrove crab meat processing
}

\author{
Masayoshi OGAWA ${ }^{1 *}$, Ana Irene Martins da SILVA ${ }^{1}$, Norma Barreto Perdigão OGAWA ${ }^{1}$, \\ Everardo Lima MAIA ${ }^{1}$, Maria Lúcia NUNES ${ }^{2}$
}

\begin{abstract}
Resumo
A carne congelada de caranguejo uçá (Ucides cordatus) é encontrada com facilidade nas lojas especializadas em pescados ou supermercados em Fortaleza (Nordeste, Brasil). Neste trabalho, uma inovação no processamento é proposta através da utilização da máquina SIAC (Sistema de Imobilização e Abate de Crustáceos), como uma alternativa menos traumatizante e mais higiênica para morte e extração da carne de caranguejo. Esta técnica provoca a imobilização do animal, com ou sem sua morte, através de pulsos elétricos controlados. Visando também reduzir os riscos à saúde dos consumidores, foi investigado o efeito da pasteurização sobre as carnes de caranguejo extraídas de modo artesanal e em laboratório. O rendimento de carne em relação ao peso do animal vivo foi influenciado pelo uso da máquina SIAC (25,1\%). Sem o uso da mesma foi de $18,9 \%$. Quanto ao rendimento em relação ao peso do animal inteiro cozido foi de 28,3 e $21,2 \%$ com e sem o uso da maquina, respectivamente. Os caranguejos imobilizados na máquina SIAC, após serem cozidos, soltaram a carne mais facilmente das carapaças, o que favoreceu o rendimento. Foi constatada a eficiência da pasteurização no processamento da carne de caranguejo através da eliminação de coliformes fecais e totais, bem como a redução na contagem total bacteriana.

Palavras-chave: caranguejo uçá (Ucides cordatus); pasteurização; rendimento, SIAC.
\end{abstract}

\begin{abstract}
Frozen mangrove crab (Ucides cordatus) meat may be purchased from a number of supermarkets or seafood retailers in Fortaleza (Northeastern Brazil). The present study proposes an improvement to crab meat processing, in the form of a crustacean immobilization and execution apparatus (SIAC), as a more sanitary and less traumatizing alternative for slaughtering and extracting the meat of mangrove crabs. The device stuns and/or executes the animals using controlled electrical pulses. The effects of pasteurization on crab meat extracted artisanally and in the laboratory were evaluated in order to minimize health risks to consumers. The two extraction techniques presented different yields: 18.9 versus $25.1 \%$, respectively, in relation to the weight of the live animal. The corresponding figures in relation to the weight of whole cooked crabs were 21.2 and $28.3 \%$. The meat of crabs stunned with the apparatus (SIAC) was easier to remove from the carapace. Pasteurization was shown to be an efficient means of eliminating fecal and total coliforms, as well as of reducing total bacterial count.

Keywords: mangrove crab (Ucides cordatus); pasteurization; yield; SIAC.
\end{abstract}

\section{Introdução}

Caranguejo uçá, Ucides cordatus (LINNAEUS, 1763) é um crustáceo de mangue que pode ser encontrado em ambientes estuarinos onde escava suas galerias no sedimento inconsolidado. Por apresentar um grande porte na fase adulta, essa espécie é apreciada como alimento em várias regiões brasileiras, possuindo, portanto, grande importância econômica (HATTORI et al., 2003).

Segundo Melo (1996), esta espécie encontra-se distribuída em áreas de manguezais, desde a Flórida (EUA) até o Estado de Santa Catarina (Brasil). Para o Instituto Brasileiro do Meio Ambiente e dos Recursos Naturais Renováveis - IBAMA (1994), a região Nordeste do Brasil concentra o maior potencial de caranguejo uçá, ocorrendo ao longo de toda a costa e abrangendo o delta do Parnaíba até a desembocadura do Rio Jurupi, fronteira com o Estado do Pará, com exceção do litoral do Parque Nacional dos Lençóis. As principais áreas de ocorrência bem como a produção correspondem aos principais estuários dos rios da região. O Estado do Ceará, apesar de ser um grande mercado consumidor, não dispõe de grandes estoques, sendo abastecido principalmente pelo Maranhão, Piauí e Rio Grande do Norte.

Grande parte da população caiçara depende da pesca desse crustáceo, principalmente no norte e nordeste brasileiro (IVO et al., 1999). O caranguejo uçá destaca-se por sua importância econômica e ecológica nos manguezais, bem como por sua abundância e extração. Devido à pouca disponibilidade de estudos é necessária a elaboração de uma legislação de defeso mais eficaz (PINHEIRO et al., 2004).

A carne congelada de caranguejo uçá pode ser encontrada em lojas especializadas em pescados ou supermercados, embalada em envoltório plástico. Em geral, esse produto não é beneficiado em estabelecimentos licenciados pelo Serviço de

Recebido para publicação em 31/8/2006

Aceito para publicação em 18/12/2007 (001832)

1 Laboratório de Recursos Aquáticos - LARAq, Departamento de Engenharia de Pesca - DEP, Centro de Ciências Agrárias - CCA, Universidade Federal do Ceará - UFC,

Rua Marechal Rondon, 282/202, Aldeota, CEP 60175-060, Fortaleza - Ceará, Brasil, Email: ogawa@ufc.br

2 Departamento de Engenharia Química - DEQ, Universidade federal de Sergipe - UFS

* A quem a correspondência deve ser enviada 
Inspeção Federal (SIF) sendo, provavelmente, preparado sem nenhum controle higiênico durante o processamento, inclusive com a possibilidade de apresentar uma alta contaminação bacteriana (OGAWA et al., 2004).

Geralmente, nenhum padrão de qualidade da carne é obedecido, pois ela apresenta grandes quantidades de fragmentos de carapaça e cartilagem, além de coágulos de hemolinfa. Este último fator contribui para a coloração não atraente do produto comercial, facilmente observada através da embalagem plástica transparente (OGAWA et al., 2006).

No presente estudo, pretende-se processar a carne de caranguejo visando obter um produto com melhor qualidade, no qual os limites de contaminação bacteriana não ultrapassem as exigências da Agência Nacional de Vigilância Sanitária (ANVISA), através da etapa de pasteurização do produto. E, principalmente, inserindo uma inovação no método de abate do animal, utilizando a máquina SIAC (Sistema de Imobilização e Abate de Crustáceos).

\section{Material e métodos}

\subsection{Matéria-prima}

Trabalhou-se com caranguejo uçá - Ucides cordatus - e com carne cozida e congelada (comercial), ambos obtidos em Fortaleza (Nordeste, Brasil). Em novembro de 2004 foram adquiridas duas amostras de caranguejos oriundos do Delta do Parnaíba (Piauí, Brasil), ambas compostas por 15 indivíduos, sendo uma amostra submetida ao tratamento com a máquina SIAC (teste) e a outra não (controle). O número de indivíduos foi definido visando obter aproximadamente $500 \mathrm{~g}$ de carne. Seis amostras de carne comercial com pesos variando de 500 a $1000 \mathrm{~g}$, provenientes de diferentes fornecedores, no período de julho a novembro de 2004, foram utilizadas para análise comparativa da qualidade em relação às amostras de carne extraídas em laboratório (teste e controle).

\subsection{Sistema de imobilização e abate de crustáceos (SIAC)}

O sistema SIAC trata-se de uma máquina confeccionada em fibra de vidro capaz de imobilizar ou abater crustáceos imersos em água doce ou salgada, à temperatura ambiente. Este aparelho usa pulsos de corrente elétrica alternada e um reservatório de cerca de $40 \mathrm{~cm}$ de altura, podendo funcionar a 110 e 220 volts e corrente elétrica de até $30 \mathrm{~A}$. A máquina SIAC funciona continuamente por 2 minutos, sendo acionada por sensores infravermelhos que emitem um sinal sonoro indicando o início de funcionamento, para no final emitir outro sinal sonoro com três bips consecutivos indicando o término do funcionamento. Sua aplicação é monitorada para permitir somente a imobilização momentânea dos animais, sendo possível retomarem suas atividades vitais normais com o tempo. Este sistema funciona por meio de descargas elétricas descontínuas emitidas por eletrodos dentro do reservatório de água. A corrente elétrica utilizada foi de $18 \mathrm{~A}$. A voltagem e o tempo de exposição e duração dos pulsos elétricos são regulados de acordo com a espécie de crustáceo (OGAWA et al., 2007).

\subsection{Processamento do caranguejo}

O processamento para extração da carne de caranguejo uçá é mostrado no fluxograma abaixo (Figura 1).

Os caranguejos foram recebidos e lavados, quando ainda amarrados, para retirada de lama e areia com o auxílio de jato d'água, realizando-se na seleção o descarte dos exemplares mortos. Em seguida a máquina SIAC imobilizou os animais com a aplicação de pulsos elétricos.

A segunda lavagem foi realizada com escova sob água corrente. $\mathrm{O}$ processo de cocção foi realizado em recipiente de alumínio e constou da imersão dos animais em salmoura fervente a 3\%, com duração de 5 a 10 minutos, após reinício da fervura, dependendo da quantidade e tamanho utilizado. Sendo que os indivíduos variaram em tamanho de carapaça de 5,90 a $7,80 \mathrm{~cm}$. Após o cozimento foram deixados esfriar à temperatura ambiente.

A retirada da carne foi procedida, manualmente, dos pereiópodos e patas após suas separações da carapaça, em mesa de aço inoxidável com tampo de vidro fosco provida de lâmpada em baixo do vidro para facilitar a retirada de resíduos indesejáveis, como fragmentos de carapaça, hemolinfa coagulada, etc. Os manipuladores, de acordo com boas práticas de higiene, usaram vestimenta apropriada: gorros, máscaras e luvas, e as mãos foram lavadas com água clorada. Para facilitar a retirada da carne os pereiópodos foram cortados no sentido do comprimento, utilizando tesoura. As patas foram quebradas com martelo de alumínio. As carnes dos pereiópodos, patas e abdômen foram retiradas com o uso de pinças e escarificadores de aço inoxidável. Cada tipo de carne, separadamente, foi pesada para cálculo do rendimento, em relação ao peso total do animal inteiro vivo e do animal inteiro cozido.

No processo de pasteurização, a carne foi embalada em sacos de PVC, com retirada de ar obtendo-se um vácuo parcial. Os sacos foram colocados em água fervente e deixados por mais

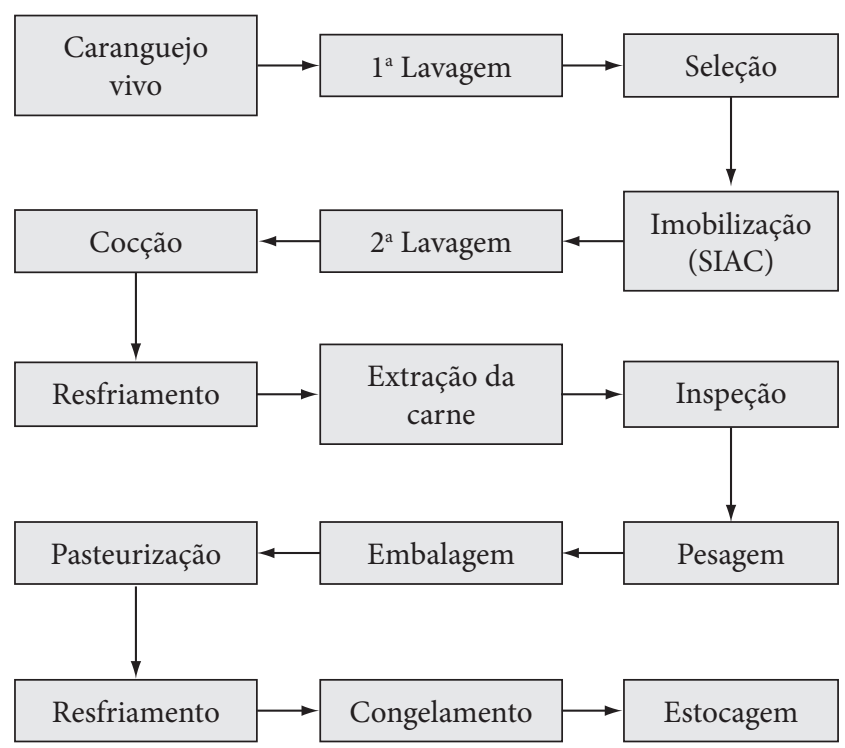

Figura 1 - Processamento da carne de caranguejo congelada extraída em laboratório e imobilizada na máquina SIAC. 
3 minutos, após a temperatura interna ter atingido $85{ }^{\circ} \mathrm{C}$. O resfriamento foi realizado em água corrente por alguns minutos até atingir a temperatura ambiente (OGAWA, 1973).

O congelamento ocorreu em refrigerador a uma temperatura de $-20{ }^{\circ} \mathrm{C}$, sendo a carne mantida estocada nesta temperatura até a realização de análises posteriores. A amostra de caranguejos utilizada como controle seguiu as etapas do processamento exemplificadas no fluxograma, exceto a etapa de imobilização.

\subsection{Análises químicas}

A composição química centesimal (proteína, lipídios, umidade e cinzas) de todas as análises foi realizada em triplicata. A proteína foi determinada pelo método micro Kjeldahl. Os lipídios foram extraídos pelo método de Soxhlet. A umidade foi determinada por dessecação em estufa à temperatura de $105^{\circ} \mathrm{C}$ e as cinzas por incineração em forno mufla a $550^{\circ} \mathrm{C}$, conforme a A.O.A.C. (1995).

\subsection{Análises microbiológicas}

As análises microbiológicas constaram de contagem padrão de bactérias mesófilas em placas, coliformes totais e coliformes fecais de acordo com FDA (1992), sendo avaliadas antes e após pasteurização. O procedimento para a identificação de bactérias patogênicas foi realizado no Laboratório Central de Saúde Pública do Estado do Ceará (LACEN), utilizando o aparelho de automação microbiológica Automatic Vitek Lab Report da marca Biomerieux.

\section{Resultados e discussão}

\subsection{Rendimento da carne de caranguejo extraída em laboratório}

No presente estudo, o rendimento médio de carne das diversas partes do caranguejo cozido em relação ao peso do animal inteiro vivo e em relação ao peso do animal inteiro cozido, imobilizado ou não pela máquina SIAC constam na Tabela 1 .

Ogawa et al. (2004), através de um processo manual e tradicional para extração da carne de caranguejo uçá, obtiveram um rendimento de $21,2 \%$ em escala de laboratório. Considerandose a soma de carne das diversas partes do corpo obteve-se um rendimento médio em relação ao peso do animal inteiro vivo e em relação ao animal inteiro cozido. A soma dos rendimentos em relação ao animal inteiro vivo com o uso do SIAC (teste) foi de $25,1 \%$, e de $18,9 \%$ sem o uso do SIAC (controle), enquanto que a soma dos rendimentos em relação ao animal inteiro cozido foi de $28,3 \%$ e de $21,2 \%$, com e sem a máquina SIAC, respectivamente.

A eficiência do SIAC na imobilização dos caranguejos foi de $100 \%$, e observou-se sensorialmente que os caranguejos amortecidos através da máquina SIAC, após cozimento, soltaram a carne mais facilmente das carapaças, o que favoreceu o maior rendimento.

\subsection{Avaliação química das amostras de carne de caranguejo}

Os dados da composição química da carne congelada comercial e extraída em laboratório constam na Tabela 2.

Os objetivos de determinar a composição química são: padronização dos produtos alimentares na base de critérios nutricionais, fornecimento de subsídios para decisões de caráter dietário, acompanhamento de processos industriais e pesquisas através de mudanças nos componentes químicos, e seleção de equipamentos certos para otimização econômico-tecnológica (CONTRERAS-GUZMÁN, 1994).

Pedrosa et al. (2001) observaram a seguinte composição química da carne cozida do caranguejo uçá: $15,01 \%$ de proteína; $0,66 \%$ de gordura; $82,80 \%$ de umidade; e $1,57 \%$ de cinzas, enquanto Cintra et al. (1999) encontraram para carne beneficiada de caranguejo uçá: $18,83 \%$ de proteína; $1,66 \%$ de gordura; $77,20 \%$ de umidade; e 2,31\% de cinzas. Já Ogawa et al. (1973) encontraram os seguintes valores em carne cozida de caranguejo uçá: 18,98\% de proteína; 2,27\% de gordura; 75,96\% de umidade; e $2,82 \%$ de cinzas, percentuais esses próximos aos encontrados em nosso estudo.

Tabela 1 - Dados sobre o rendimento da carne de caranguejo extraída em laboratório com e sem o uso da máquina SIAC.

\begin{tabular}{lccccc}
\hline \multirow{2}{*}{ Amostra } & \multicolumn{4}{c}{ Rendimento (\%) } \\
\cline { 2 - 3 } & & $\begin{array}{c}\text { Em relação ao peso do } \\
\text { animal vivo }\end{array}$ & & $\begin{array}{c}\text { Em relação ao peso do } \\
\text { animal cozido }\end{array}$ \\
\cline { 3 - 5 } \cline { 5 - 6 } Média(\%) $\pm \mathrm{dp} p$ & $\begin{array}{c}\text { Sem SIAC } \\
\text { (controle) }\end{array}$ & $\begin{array}{c}\text { Com SIAC } \\
\text { (teste) }\end{array}$ & $\begin{array}{c}\text { Sem SIAC } \\
\text { (controle) }\end{array}$ & $\begin{array}{c}\text { Com SIAC } \\
\text { (teste) }\end{array}$ \\
\hline Patas & $6,4 \pm 0,82$ & $8,5 \pm 1,81$ & & $7,2 \pm 0,85$ & $9,6 \pm 1,13$ \\
Abdômen & $6,1 \pm 0,97$ & $8,6 \pm 1,92$ & & $6,9 \pm 1,16$ & $9,7 \pm 1,13$ \\
Pereiópodos & $6,4 \pm 0,83$ & $8,0 \pm 1,37$ & & $7,1 \pm 1,35$ & $9,0 \pm 1,27$ \\
Total & 18,9 & 25,1 & 21,2 & 28,3 \\
\hline
\end{tabular}

$\mathrm{dp}=$ desvio padrão.

Tabela 2 - Composição química da carne de caranguejo congelada comercial extraída em laboratório.

\begin{tabular}{|c|c|c|c|c|}
\hline \multirow{3}{*}{$\begin{array}{c}\text { Amostra } \\
\text { Média }(\%) \pm d p\end{array}$} & \multicolumn{4}{|c|}{ Carne de caranguejo } \\
\hline & \multicolumn{2}{|c|}{ Congelada comercial } & \multicolumn{2}{|c|}{ Extraída em laboratório } \\
\hline & Sem pasteurização & Com pasteurização & Sem pasteurização & Com pasteurização \\
\hline Umidade & $75,63 \pm 4,06$ & $71,83 \pm 1,55$ & $74,48 \pm 3,65$ & $72,58 \pm 2,16$ \\
\hline Proteína & $19,62 \pm 3,41$ & $24,29 \pm 2,17$ & $20,12 \pm 2,84$ & $22,45 \pm 1,70$ \\
\hline Cinzas & $1,92 \pm 0,61$ & $1,50 \pm 0,76$ & $2,30 \pm 0,40$ & $1,61 \pm 0,18$ \\
\hline Lipídios & $2,89 \pm 1,24$ & $3,12 \pm 1,07$ & $3,31 \pm 0,27$ & $3,39 \pm 0,27$ \\
\hline
\end{tabular}

$\mathrm{dp}=$ desvio padrão. 
Comparando as amostras pasteurizadas e não pasteurizadas, no que diz respeito à composição química, nota-se que houve uma elevação do teor de lipídios e proteína e uma diminuição de umidade e cinzas em decorrência do tratamento térmico em questão.

\subsection{Avaliação microbiológica das amostras de carne de caranguejo uçá}

Os valores referentes à quantidade de coliformes e contagem de bactérias das amostras de carne congelada comercial e extraída em laboratório antes e após pasteurização constam na Tabela 3.

$\mathrm{Na}$ pesquisa de coliformes totais nas 6 amostras de carne congelada comercial, observou-se que 5 amostras estavam acima de $5 \times 10^{2} \cdot \mathrm{g}^{-1}$, enquanto para coliformes fecais todas as amostras situaram-se fora do padrão da ANVISA (BRASIL, 2001), para coliformes fecais em carne de siri e similares cozidos, que é de $5 \times 10 \cdot \mathrm{g}^{-1}$. A contagem padrão de bactérias mesófilas em placas para pescado não está presente no padrão da ANVISA (BRASIL, 2001), mas segundo a CNNPA (BRASIL, 1978), o máximo permitido deve ser de $10^{6}$ UFC.g- ${ }^{-1}$. Assim, apenas 1 amostra apresentou contagem padrão inferior a este padrão estabelecido.

No tocante às duas amostras de carne extraídas em laboratório todas se situaram abaixo de $5 \times 10^{2} \cdot \mathrm{g}^{-1}$ para coliformes totais e um pouco acima do padrão quanto a coliformes fecais. Porém, o processo de pasteurização mostrou-se eficaz, pois após pasteurização todas as amostras (congelada comercial e extraída em laboratório) apresentaram valores ausentes. Na contagem de bactérias mesófilas as amostras extraídas em laboratório estavam dentro do padrão, antes e após pasteurização. Após pasteurização, todas as amostras (congelada comercial e extraída em laboratório) apresentaram contagem padrão $<10$ UFC.g ${ }^{-1}$.

A presença de bactérias do grupo coliformes termotolerantes ou fecais no alimento é interpretada como indicador de contaminação fecal, ou seja, de condições higiênico-sanitárias insatisfatórias (BRITO et al., 2003).

Segundo Vieira $(2004)^{20}$, um dos grandes problemas no processamento dos caranguejos é o tratamento manual utilizado para se retirar as carnes das patas e do corpo do animal depois do mesmo ter sofrido um cozimento rápido. Essa operação pode ser fonte de contaminação, principalmente de estafilococos. $\mathrm{O}$ uso de luvas e a aplicação de boas práticas de higiene, aliados à manutenção das temperaturas adequadas e esfriamento rápido da carne, evitam esse problema no processamento de caranguejo.

Das amostras enviadas ao LACEN para a identificação de possíveis bactérias patogênicas no aparelho de automação microbiológica, foi constatada a ausência de Salmonella sp., Staphylococcus aureus, Vibrio parahaemolyticus e V. cholerae em todas as amostras.

Sabe-se que os métodos microbiológicos podem mostrar uma imagem da qualidade higiênica do animal, padronizar a higiene durante a manipulação e elaboração de produtos, e detectar a possível presença de bactérias ou organismos de importância para a saúde pública (HUSS, 1988). Ainda de acordo com Huss (1988), a contagem padrão em placas dará uma medida do grau de contaminação microbiana e as condições de higiene aplicadas durante a manipulação e elaboração de produtos oriundos de pescado.

De acordo com Cintra et al. (1999), devido à carne de caranguejo ser um alimento facilmente perecível, propício à proliferação de microrganismos, e os processos de extração para comercialização serem todos manuais, muitas vezes sem a devida higiene no manuseio, acabam contaminando o produto e podem trazer graves riscos de saúde ao consumidor.

Vale salientar que o Brasil é responsável pela parte de lagosta e caranguejo no Comitê do Codex Alimentarius (2006) sobre pescado e seus produtos processados, participando do comitê há mais de 8 anos, para definir estes produtos juntamente com inspetores do Governo Federal. É de grande valia se estabelecer o controle higiênico-sanitário destes produtos, já que agregará valor aos mesmos.

Neste trabalho constatou-se a eficiência, em escala laboratorial, da pasteurização no processamento da carne congelada de caranguejo eliminando-se coliformes fecais e totais, observando-se uma significativa redução na contagem total bacteriana. Ressaltamos que após pasteurização, o produto apresentou um aspecto mais atraente (coloração mais clara), permanecendo com o congelamento. Sugere-se que a embalagem deverá ser com material que suporte tratamento térmico (pasteurização) como PVC ou "retort pouch", e de preferência fechada a vácuo. $\mathrm{O}$ congelamento deve ser rápido e abaixo de $-20^{\circ} \mathrm{C}$, com estocagem abaixo de $-18^{\circ} \mathrm{C}$.

Tabela 3 - Dados sobre coliformes e contagem bacteriana em amostras de carne de caranguejo congelada comercial e extraída em laboratório.

\begin{tabular}{|c|c|c|c|c|c|c|}
\hline \multirow[t]{2}{*}{ Amostra } & \multicolumn{3}{|c|}{ Sem pasteurização } & \multicolumn{3}{|c|}{ Após pasteurização } \\
\hline & $\begin{array}{c}\text { Coliformes totais } \\
\text { NMP.g }^{-1}\end{array}$ & $\begin{array}{c}\text { Coliformes fecais } \\
\text { NMP.g }\end{array}$ & $\begin{array}{l}\text { Contagem padrão de } \\
\text { bactérias UFC.g-1 }\end{array}$ & $\begin{array}{c}\text { Coliformes totais } \\
\text { NMP.g }^{-1}\end{array}$ & $\begin{array}{c}\text { Coliformes fecais } \\
\text { NMP.g }^{-1}\end{array}$ & $\begin{array}{l}\text { Contagem padrão de } \\
\text { bactérias UFC.g- }\end{array}$ \\
\hline 1 & $2,3 \times 10^{2}$ & $2,3 \times 10^{2}$ & $1,8 \times 10^{6}$ & Aus & Aus & $<10$ \\
\hline 2 & $2,4 \times 10^{8}$ & $2,4 \times 10^{8}$ & $2,8 \times 10^{8}$ & Aus & Aus & $<10$ \\
\hline 3 & $2,4 \times 10^{4}$ & $2,3 \times 10^{2}$ & $2,9 \times 10^{6}$ & Aus & Aus & $<10$ \\
\hline 4 & $2,4 \times 10^{4}$ & $2,4 \times 10^{4}$ & $1,8 \times 10^{6}$ & Aus & Aus & $<10$ \\
\hline 5 & $9,3 \times 10^{3}$ & $4,3 \times 10^{3}$ & $1,6 \times 10^{5}$ & Aus & Aus & $<10$ \\
\hline 6 & $1,5 \times 10^{4}$ & $4,3 \times 10^{3}$ & $1,5 \times 10^{6}$ & Aus & Aus & $<10$ \\
\hline 7 & $4,3 \times 10^{2}$ & $9,1 \times 10$ & $1,5 \times 10^{5}$ & Aus & Aus & $<10$ \\
\hline 8 & $9,1 \times 10$ & $5,3 \times 10$ & $1,5 \times 10^{4}$ & Aus & Aus & $<10$ \\
\hline
\end{tabular}

Amostras 1 a 6 = comercial; 7 = controle; 8 = teste; $\mathrm{NMP}=$ número mais provável; $\mathrm{UFC}=$ unidade formadora de colônias; $g$ = gramas; $\mathrm{e}$ Aus = Ausente . 
A eficiência da pasteurização, em escala laboratorial, também foi constatada por Ogawa et al. (1973) durante o processamento da carne congelada do caranguejo uçá, na qual foi observada uma redução na contagem de bactérias de $10^{6}$ para $10^{4}$, sendo mantida neste patamar durante 3 meses de estocagem.

\section{Conclusões}

- Os animais imobilizados com o método SIAC soltaram a carne mais facilmente, o que favoreceu o rendimento;

- O rendimento de carne utilizando a imobilização dos animais por pulsos elétricos (Método SIAC) foi considerado satisfatório quer em relação ao animal inteiro vivo, quer em relação ao animal inteiro cozido;

- O processo de pasteurização foi eficiente, eliminando de maneira eficaz os coliformes presentes na carne congelada comercial e/ou extraída em laboratório, e diminuindo significativamente a contagem padrão de bactérias; e

- Verificou-se a ausência de bactérias patogênicas, tais como: Salmonella sp., Staphylococcus aureus, Vibrio parahaemolyticus e V. cholerae em todas as amostras.

\section{Agradecimentos}

Ao Conselho Nacional de Desenvolvimento Científico e Tecnológico - CNPq e à Fundação Cearense de Apoio ao Desenvolvimento Científico e Tecnológico - FUNCAP, pelo apoio financeiro. Aos Engenheiros de Pesca: Cláudia Cinthia dos Santos Oliveira, Francisca Francineuma Fernandes Basílio, Ianna Wivianne Fernandes de Araújo e Francisco Walber Soares Araújo, e aos estudantes de Engenharia de Pesca: Nino Nhanca, Aretha Alves Oliveira e Marianna Moreira, pelo apoio e colaboração nas análises laboratoriais.

\section{Referências bibliográficas}

A.O.A.C. Association of Official Analytical Chemists. Official methods of analysis. $16^{\circ}$ ed., Arlington: AOAC International, 1995. 1141p.

BRASIL. Ministério da Saúde. Comissão Nacional de Normas e Padrões para Alimentos - CNNPA. Resolução n ${ }^{\circ}$ 13/78, 31 de março de 1978. Aprova a revisão dos padrões microbiológicos. Diário Oficial da República Federativa do Brasil. Brasília, DF, 25 julho 1978. Secção 1, p. 269-73.

. Ministério da Saúde. Agência Nacional de Vigilância Sanitária - ANVISA. Resolução n 12, 02 de Janeiro de 2001. Dispõe sobre padrões microbiológicos. Diário Oficial da República Federativa do Brasil. Brasília, DF, 02 jan. 2001. Seção 1, p.48.

BRITO, G. et al. Avaliação da qualidade microbiológica de hambúrgueres e cachorros-quente comercializados por vendedores ambulantes no município de Juazeiro do Norte, CE. Higiene Alimentar, São Paulo, v. 17, n. 110, p. 90- 94, 2003.

CINTRA, I. H. A. et al. A catação do caranguejo-uçá Ucides cordatus (Linnaeus, 1763), no município de São Caetano de Odivelas/Pará:
Aspectos sócio-econômicos, descrição do beneficiamento artesanal e composição química. In: XI CONGRESSO BRASILEIRO DE ENGENHARIA DE PESCA, Anais... v. 1, p. 323-330. Olinda, 1999.

CODEX ALIMENTARIUS COMMISSION - FAO-UN/WHO. Codex Committee on Fish and FisheriesProducts. Alesune, Norway, 18-22 sept. 2006.

CONTRERAS-GUZMÁN, E. S. Bioquímica de pescado e derivados. Jaboticabal: FUNEP, p. 409,1994.

FDA. Food and Drug Administration. Bacteriologycal analytical manual. 7 ed. Arlington: A.O.A.C. International, 1992. 529 p.

HATTORI, G. Y. et al. Fertilidade do caranguejo de mangue Ucides cordatus (Linnaeus) (Crustacea, Brachyura, Ocypodidae), em Iguape (São Paulo, Brasil). Rev. Bras. Zool., Curitiba, v. 20, n. 2, p. 309-313, jun. 2003.

HUSS, H. H. Evaluacion de la Calidad del Pescado. In: El pescado fresco: su Calidad y cambios de calidad. Colección FAO: Pesca, Organización de las Naciones Unidas para la Agricultura y la Alimentación. Roma: FAO, 1988. p. 61-75.

IBAMA. Lagosta, caranguejo uçá e camarão do nordeste. Brasília: Séries estudos-pesca 125-140, (Coleção Meio Ambiente,10), 1994.

IVO, C. T. C. et al. Sinopse das observações sobre a bioecologia e pesca do caranguejo uçá, Ucides cordatus cordatus (Linnaeus, 1763), capturado em estuários de sua área de ocorrência no Brasil. Boletim Técnico Científico do CEPENE, Tamandaré, v. 7, n. 1, p. 9-52, 1999.

MELO, G. A. S. Manual de identificação dos brachyura (Caranguejos e Siris) do litoral brasileiro. São Paulo, Ed. Plêiade/FAPESP, 1996, $604 \mathrm{p}$.

OGAWA, M. et al. Industrialização do caranguejo uçá, Ucides cordatus (Linnaeus). I - técnicas para o processamento da carne. Arq. Ciên. Mar, Fortaleza, v. 13, n. 1, p. 31-37, 1973.

Melhoramento no processo de beneficiamento da carne de caranguejo processada artesanalmente. In: VII ENCONTRO NACIONAL DE EDUCAÇÃO AMBIENTAL EM ÁREAS DE MANGUEZAL, Anais... Resumos, São Francisco do Sul, 2004.

Uso do sistema SIAC e sua influência no rendimento e qualidade da carne de caranguejo. In: XX CONGRESSO BRASILEIRO DE CIÊNCIA E TECNOLOGIA DE ALIMENTOS, Anais... Resumos, Curitiba, 2006.

Eletric paralyzation and reducion of weight loss in the processing of round-coked spiny lobsters. Ciênc. Tecnol. Aliment., Campinas, v. 27 n. 1, p. 125-129, jan./mar. 2007.

PEDROSA, L. F. C. et al. Composição centesimal e de minerais de mariscos crus e cozidos da cidade de Natal/RN, Ciênc. Tecnol. Aliment., Campinas, v. 21, n. 2, p. 154-157, may./aug. 2001.

PINHEIRO, M. A. A. et al. Projeto caranguejo: contribuição ao conhecimento biológico do caranguejo uçá na baía da Babitonga (SC). In: VII ENCONTRO NACIONAL DE EDUCAÇÃO AMBIENTAL EM ÁREAS DE MANGUEZAL, Anais... Resumos, São Francisco do Sul, 2004.

VIEIRA, R. H. S. F. Microbiologia, higiene e qualidade do pescado. São Paulo: Livraria Varela. 2004. 380 p. 